REVIEW

\title{
Current dilemmas in overseas doctors' training
}

\author{
D P S Sandhu
}

Postgrad Med J 2005;81:79-82. doi: 10.1136/pgmi.2004.024547

International medical graduates (IMGs) are a remarkably successful professional group in the United Kingdom making up to $30 \%$ of the NHS work force. Their very success and media publicity about general practice and consultant shortages, has led to a large influx of inexperienced doctors seeking training opportunities in competitive specialties. In 2003 a record 15549 doctors joined the medical register of which 9336 doctors were non-European Economic Area citizens. The number of candidates sitting PLAB part 1 and part 2 in 2003 rose by $267 \%$ and $283 \%$ respectively compared with 2001 . Changes to Department of Health, Home Office, and deanery regulations with expansion of medical schools, implementation of European Working Time Directive, Modernising Medical Careers, and the future role of the Postgraduate Medical Education and Training Board, will have an important impact on IMGs' training. Dissemination of realistic information about postgraduate training opportunities is important as the NHS for some time will continue to rely on IMGs.

Correspondence to:
Mr D P S Sandhu, LNR
Deanery, Lakeside House,
4 Smith Way, Grove Park,
Enderby, Leicester LE19
1SS, UK; linda.bennet+@
uhl-tr.nhs.uk

Submitted 25 May 2004 Accepted 26 May 2004
$\mathrm{O}$ verseas doctors, now called international medical graduates (IMGs), are an important and proven asset for the United Kingdom with an estimated $22140^{1}$ working in England alone in the NHS. However, a great many changes are currently underway in the training of UK doctors many of which will have implications for IMGs in terms of their training needs and preparation for work in the UK.

There will need to be an increase in the medical workforce as UK standards of delivery of health care and associated reforms are driven forward by specified time capped government targets and requirements of the European Working Time Directive (EWTD). ${ }^{2}$ Five new UK medical schools will have opened by 2005 and the number of medical school places will rise to 6873 , giving a $31 \%$ increase since the year 2000 and a huge 58\% increase since $1995 .^{3}$ This increased number, however, is still short of the new graduates required for the UK medical workforce of the future.

Over the past few years, the GMC has granted on average about 11000 new registrations each year. Of these, about 4500 were UK qualified doctors, 1500 were European Economic Area (EEA) qualified, who benefit under the free movement provisions of European Union Law, and 5000 were IMGs. The biggest sector of registered doctors and hence potential workforce is, therefore, that of IMGs.
GMC registration does not necessarily equate with job opportunities and there can be discrepancies in the figures such that we cannot take the number of registrations as indicative of the actual size of the potential workforce. There are instances, for example, when individual doctors are granted registration more than once in a single year. Nevertheless, there will clearly remain a big shortfall in the number of UK trained doctors that are required for service delivery and a heavy reliance on IMGs.

In 2003 there was a particularly large increase in new registrations with the GMC when a total of 15549 doctors joined the Medical Register. Of these, 4443 were from the UK, 1770 were from the EEA, and a record 9336 were IMGs. ${ }^{4}$ This increase is beneficial for the UK as it means there is a much improved potential medical workforce. For IMGs the implication is that jobs will be more competitive and they need to be aware of what they need to do to ensure they have realistic expectations and opportunities for employment. The figures for 2003, however, are not necessarily indicative of a future huge rise in registered doctors. This is because graduates from the 22 universities in seven countries who were exempt from the Professional and Linguistic Assessments Board examination (PLAB), and able to apply for full registration, applied in large numbers pre-empting the change in rules. These rules now mean that all IMGs, irrespective of where they qualified, will have to take PLAB with resulting limited registration.

The statistics show not only the UK's continuing need for IMGs but, also, that the UK is overwhelmingly attractive to IMGs. For some years this will continue to be the case as the NHS Plan seeks to create 7500 more consultants and 2000 more general practitioners and there are insufficient numbers of UK graduates to fill these posts. ${ }^{5}$

There is also the difficulty of retaining doctors in their profession. A significant number of inner city general practitioners will retire in the next three years. In addition to early retirement, the impact of flexible or part time working with the Improving Working Lives ${ }^{6}$ initiative, the reduction in hours as per the EWTD, and a drive to a more supernumerary form of junior training with a consultant based service, means that IMGs will be an important means of achieving a rapid increase of the medical workforce.

\footnotetext{
Abbreviations: IMG, international medical graduate; EWTD, European Working Time Directive; EEA, European Economic Area; PLAB, Professional and Linguistic Assessments Board; PFTV, permit free training visa; CA, clinical attachment; CCST, certificate of completion of specialist training; RITA, record of intraining assessment
} 
IMGs are still portrayed in the media as struggling to achieve their goals of having a medical career in the UK. ${ }^{7-11}$ In fact they are probably one of the most successful professional groups in the UK, providing a third of the medical workforce. In England in 2003, 38\% of senior house officers (SHO), $32 \%$ of specialist registrars ( $\mathrm{SpR}$ ) - that is, National Training Number holders (NTNs) and Fixed-Term Training Appointments (FTTAs) -and 19\% of consultants were IMGs. ${ }^{1}$ Hence, in a highly competitive field at consultant level, almost one in five of all consultants are IMGs. This is despite time constraints placed on IMGs as they have to pass the International English Language Testing System (IELTS), and PLAB. Such time erodes into opportunities for research and audit and, therefore, IMGs' curriculum vitae can be weak in publications resulting in difficulty in being short listed despite appropriate clinical experience. Yet they are a highly successful, motivated group with a certain doggedness for survival from whom the rest of us, including UK trainees can learn. Part of the credit for their success goes to the improvement in dissemination of information about training and career opportunities and a clear organisational and support pathway.

\section{ORGANISATIONAL SUPPORT}

The IELTS and PLAB part 1 can be taken abroad reducing the expenses incurred by IMGs. In 2001, 4682 candidates sat PLAB part 1 of whom 2280 sat the examination abroad, an increase of $87 \%$ over the previous year. Overall, even then, there was a $36 \%$ rise from the previous year in IMGs sitting the examination. The pass rate for part 1 was $60 \%$, a high proportion. The number of candidates sitting part 2 of PLAB in 2001 also showed an increase of $72 \%(n=2323)$ over the previous year with a pass rate of $84 \%$. This trend continues and in 2003 a record 12513 IMGs sat PLAB part l. Of these, 3498 candidates sat part 1 in the UK and 9015 (72\%) sat overseas, 6375 of them in India. The demand for PLAB part 2 was also higher and 6580 sat PLAB part 2 . The pass rates were similar to 2001 at $62 \%$ for PLAB part 1 and $79 \%$ for PLAB part $2 .^{4}$

In the UK there is close liaison between the postgraduate deans, NHS Executive (NHSE), and the Home Office in providing support for IMGs. ${ }^{12}$ Every deanery now has an associate dean or representative with special responsibility for IMGs, including responsibility for permit free training visa forms (PFTV). Verification by the deanery of the information on the PFTV should lead to more efficiency in dealing with visas by the Home Office. The deanery also provides the IMGs a training handbook or web based information.

From 2000, uniquely, fully funded induction courses by the NHSE for IMGs who are in their first post, or have passed IELTS and PLAB, have been a spectacular success, leading to the Certificate of UK Induction (CUKI). CUKI leads to a rapid introduction to NHS culture, addresses risk management issues, and, for some, has directly led to clinical attachments and their first SHO post.

\section{CLINICAL ATTACHMENTS (CAS)}

CAs are an opportunity to learn about UK medical practice, competitive ratios regarding job applications, and how to sharpen up clinical and presentation skills to gain success at interviews. These are optimally undertaken just before PLAB part 2, and are a useful and practical way of gaining knowledge of general practice and hospital care. CAs should be at least at the level of final year medical students and, therefore, these doctors should be allowed to examine patients, assist at operations, pass catheters, and undertake venepuncture.
For clinical attachments, IMGs need to be screened by occupational health and sign a confidentiality agreement that will give them trust indemnity. Trusts may charge for administration and occupational health expenses.

Encouragingly a feature of CAs is that they can lead to research, audit projects, and a UK reference, which all help when applying for competitive posts. However, IMGs must realise that they are not automatically entitled to CAs. The supervision of these posts is based on the goodwill of consultants. Requests are granted depending on current undergraduate and postgraduate attachments already in place and the availability of consultants. If consultants receive large numbers of emails and letters from IMGs they will be unable to respond. It is more appropriate to seek contacts from acquaintances already working and then personally request an interview with a specifically targeted specialty and consultant.

\section{PERMIT FREE TRAINING VISAS}

Pre-registration house officers and SHOs are permitted one and four years PFTV respectively. This is to avoid IMGs drifting. The old scenario of a doctor being an SHO for nine years must not be permitted as such a medical career would be destroyed. There is a large pool of EEA doctors and IMGs who wish to train and work in the UK and posts, especially in the popular specialties, are highly sought after. A signal, such as failure to progress, must be taken as a need for action and these doctors need to be counselled about developing other educational goals such as postgraduate examinations, higher degrees, presentations, publications, change of specialty, and, equally important, to return home. In the future, with Modernising Medical Careers and capped training, such decisions should be more tightly governed. Currently the four year PFTV cannot be extended and, in some specialties where postgraduate examinations can only be taken while in post (for example, psychiatry, which is a shortage specialty), this can be problematic. It would be helpful if postgraduate examinations can be taken when the candidates have completed appropriate training posts satisfactorily, even though they may no longer be in post.

Another aspect of PFTV extensions is that it can only be extended for the period of the post. This can create what IMGs feel to be intolerable bureaucratic time and travel pressures, as short time contracts would result in multiple trips to the Home Office for visa extensions. It would be preferable if IMGs were given the choice to have a minimum of a year's PFTV, irrespective of the length of the post, providing they accept that such additional time would erode into their four year SHO training time. This would help financially as, from 1 August 2003, there is a charge for each visa extension of $£ 155$ for postal applications, and $£ 250$ for the premier same day personal caller service. ${ }^{13}$

For SpRs, provided their record of in-training assessments (RITA) are satisfactory, their PFTV is extended until certificate of completion of specialist training (CCST) is obtained. After obtaining their CCST, IMGs are eligible to apply for consultant posts in open competition on a work permit. Unlike locum appointments for service (LAS), two years of satisfactory completion in a locum appointment for training (LAT) can count towards a CCST.

\section{FIXED TERM TRAINING APPOINTMENTS (FTTA)}

Many IMGs, at the completion of their four year basic training, remain inexperienced without any specialist training and, synchronously, hit the bottleneck of Type l SpR training (NTN). An alternative is to get an FTTA post (FTN). These posts are for IMGs and EEA doctors who have completed their basic training, and seek a specific educational goal. Such posts last for one to two years and do not 
lead to a CCST. UK trainees are not allowed to apply for these posts unless they have completed their CCST. Repeated extension of such posts deprives other IMGs of getting experience at SpR level, and this fact should be taken into account by programme directors to ensure that opportunities exist for new junior trainees. It will also help IMGs if, on completion of their educational goal, they are given a certificate to confirm this achievement.

IMGs in non-consultant career grade posts (NCCG) and in FTTA posts may have an opportunity to apply for year 4 or 5 NTN posts. This will be dependent on recognition of equivalence of previous training. In line with European and UK legislation, the Specialist Training Authority (STA), through the Royal Colleges, will determine how much nonUK and UK non-substantive training may count towards the award of a CCST. The committee that deals with this at present is the Specialist Advisory Committee (SAC) of that specialty. This role, in the future, will be taken over by the newly formed Postgraduate Medical Education and Training Board (PMETB). This body will try and assess whether general professional training has been completed, and whether the specialist training is comparable with UK training at a similar stage, with documentary confirmation of any such training. For IMGs this is a radical change and is welcomed as there will now be an independent organisation with a specific task to address equivalence of experience against training. Time spent in honorary and locum consultant posts will not contribute to a CCST. International recruitment to consultant posts has to undergo a similar process of vetting, currently by the SAC (in future by PMETB), of training, experience, qualifications, and original documents, including log books.

\section{TRAINING IN GENERAL PRACTICE (GP)}

This is the area of the most radical change in training affecting IMGs. Since November 2001 restrictions on the funding of GP registrar posts were lifted and all such posts are funded by the NHSE. IMGs were required to be fully registered with the GMC to take up a GP registrar post but now, in England, can do so with limited registration. ${ }^{14}$ GP training in its entirety will be on a PFTV without the need for a training work experience permit (TWES).

\section{TRUST GRADE DOCTORS}

As a consequence of the EWTD and the moratorium on new SHO posts, the number of doctors required to deliver the health service, particularly in the acute specialties, is under strain, especially as all out of hours rotas have to be New Deal $^{15}$ compliant. To comply with the EWTD and new on-call rotas, trusts have little choice but to appoint NCCG and trust grade doctors or clinical fellows. The trust grade doctors are therefore in posts that do not have the postgraduate dean's or Royal College approval, the very bodies that are responsible for the delivery of a high quality medical workforce. However, there is a difference between what were traditionally called service posts and those approved for training. Currently to be attractive for recruitment, trust grade doctor posts have to be of high quality in terms of delivering service and training. Such posts therefore, are usually subject to the Whitley Council guidelines for training and service, although not legally required to do so. They may indeed be part of a SHO rotation where it is not clear which part of the rotation is the trust grade post. Some of these posts are now recognised for the purpose of taking postgraduate examinations. Additionally, some trust grade SHO posts have been approved for training to cater for the additional number of General Practice Vocational Training Schemes that are required to train more GPs, and if they have been incorporated into foundation year 2 prototypes. When it comes to short listing and acknowledgement of UK experience, IMGs would like to be given recognition for the effort they have put into these posts.

\section{SPONSORSHIP SCHEMES}

International sponsorship schemes, which are predominantly run by the British Council and the Royal Colleges can function on the basis of dual sponsorship of IMGs by the home country and the UK, or an individual sponsorship scheme, the details of which will have been ratified by the registration committee of the GMC. Selection should consist of (1) a robust interview in their own country to meet equal opportunities legislation, (2) achievement of the required IELTS score of a minimum of 7 in every band, (3) by inference, sponsored doctors should not be UK nationals and, only exceptionally, have EU nationality, and (4) sponsored doctors are still required to satisfy the same criteria as any other applicant for limited registration. This means they must provide objective evidence of their capability to practice. Successful sponsored IMGs are then exempt from taking the PLAB test.

These sponsorship schemes, in the past, ran into difficulty as the number of sponsored doctors outstripped the posts available for training. At present, $80 \%$ of doctors currently sponsored are at SHO level. Some of the schemes do not appoint to specific posts and sponsored applicants will need to undergo a competitive interview. Future direct placements of sponsored IMGs into specifically created FTTA posts, in specialties that have additional training capacity, will do much to increase training opportunities and fellowship exchanges for this group.

\section{REGISTRATION WITH THE GMC}

The GMC are currently undertaking a Registration and Licensure Review. The review is at draft stage at present but it is probable that limited registration will, in the future, be abolished and replaced with a single general training licence covering all doctors, irrespective of whether they have qualified in the UK, EEA, or overseas. This will be a fairer system, although IMGs will need to provide evidence of their capability to practice. All doctors, including IMGs, will require regular revalidation.

\section{MODERNISING MEDICAL CAREERS}

A consequence of the Unfinished Business-SHO reform paper, ${ }^{16-17}$ has been wide ranging discussion on seamless training from foundation school to consultant, with its emphasis on time capped competency based training. The matched foundation year 1 (FYl, PRHO) and foundation year 2 (FY2, SHO year 1) programmes will need a minimum of an additional $30 \%$ FY2 posts to accommodate IMGs who have generally started their careers from SHO year l posts. Having gained the competencies of FY2, IMGs, like their UK counterparts, will have to apply for seamless training to gain a certificate of completion of training (CCT). All trainees, if unsuccessful in getting a CCT programme, would then need to apply for alternative, or less competitive, specialties thus fulfilling the service delivery needs of the less popular specialties. The time frame will be much tighter and an understanding of competitive ratios for posts will be important. The formation of PMETB and future determination of how much non-UK and UK non-substantive training may count, will overhaul the criteria for admission to the specialist register, and reform the NCCG group.

For IMGs the current medical education reforms will do much to simplify the career aspirations, rewards, and integration of IMGs in the UK. It is however important for IMGs to realise that while the UK is short of doctors, the need is for doctors with good communication and clinical skills 
necessary to deliver the NHS Plan. Passing IELTS and PLAB, doing a clinical attachment and an audit project is just the beginning. The very success of IMGs has attracted many overseas applicants and, in the current competitive environment, poor information about training opportunities in the UK is no longer an acceptable excuse.

Funding: none.

Conflicts of interest: none declared.

\section{REFERENCES}

1 Department of Health. NHS hospital, public health medicine and community health service medical and dental workforce census: England at 30 September 2003. London: DoH, 2003.

2 Department of Health. Protecting staff; delivering services: implementing the European Working Time Directive for doctors in training. HSC 2003/001. London: DoH, 2003.

3 McManus IC. Medical school applications-a critical situation. BMJ 2002;325:786-7.

4 General Medical Council. 2003 statistics. http://www.gmc-uk.org.

5 Department of Health. The NHS Plan: a plan for investment, a plan for reform. Cm 4818-I. London: DoH, 2000.
6 Department of Health. Improving working lives in the NHS. HSC 1999/218. London: DoH, 1999

7 Richards T. The overseas doctors training scheme: failing expectations. BMJ 1994:308:1627-31.

8 Welsh C. Training overseas doctors in the United Kingdom. BMJ 2000;321:253-4

9 Sridhar MK. What is the future for overseas graduates? BMJ 2000;320:307.

10 Anwar R. Overseas doctors need more attention. BMJ 2002;325:1369

11 Rupalee S. My experience as the spouse of an overseas doctor. BMJ Careers 2002;Dec:s212.

12 Sandhu DPS, Johnson N. Integrating refugee doctors into the NHS. Ann R Coll Surg Engl Supp 2002;84:348-9.

13 Home Office. Information about new charges. London: IND Communications Unit, 2003

14 General Medical Council. Joint Committee on postgraduate training and general practice. http://www.jcptgp.org.uk/certification/registration.asp.

15 Department of Health. New Deal. http://www.dh.gov.uk/ PolicyAndGuidance/HumanResourcesAndTraining/ModernisingPay/ JuniorDoctor/Contracts.

16 Donaldson L. Unfinished business. Proposals for reform of the senior house officer grade. A paper for consultation. London: DoH, 2002.

17 Department of Health. Modernising medical careers. The response of the four UK Health Ministers to the consultation on "Uunfinished business. Proposals for reform of the senior house officer grade". London: DoH, 2003.

\section{IMAGES IN MEDICINE}

\section{Bilateral dislocation of temperomandibular joints in a child: easily missed with the dummy in}

B ateral dislocation of the temperomandibular joints are rare in children. The classic signs of this condition, anterior open bite, protruded mandible, and drooling are all indistinct in this child until the dummy is removed. As a result she was initially diagnosed as having mumps because the subtle sign of the displaced mandibular condyle heads bulging in the pre-auricular region was misinterpreted as parotid swellings (arrowed in both pictures). Unwell children should have the orofacial region fully examined, which may require removal of the dummy. Not all pre-auricular swellings are parotid in origin.

L Cascarini, M Cameron Department of Maxillofacial Surgery, Queen Victoria Hospital, East Grinstead, UK

Correspondence to: Mr L Cascarini, Department of Maxillofacial Surgery, Queen Victoria Hospital, East Grinstead RH19 3DZ, UK; Icascarini@hotmail.com

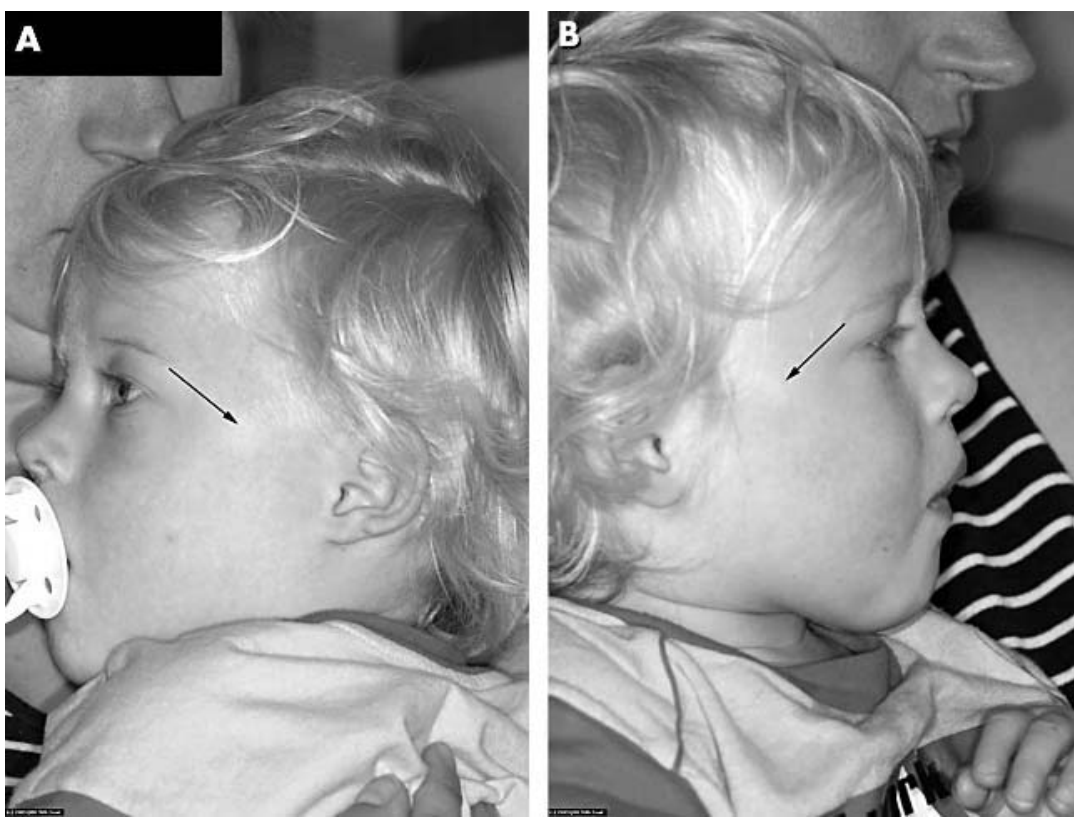

Figure 1 (A) With the dummy in the only sign of dislocated TMJs is the pre-auricular swelling, arrowed; (B) with dummy removed, clearly showing the classic signs of dislocated TMJs. 